\title{
Paediatric snakebite envenoming: recognition and management of cases
}

\author{
Jacqueline Le Geyt (10 ,' Sophie Pach, ${ }^{2}$ José María Gutiérrez, ${ }^{3}$ \\ Abdulrazaq Garba Habib, ${ }^{4}$ Kalana Prasad Maduwage, ${ }^{5}$ Timothy Craig Hardcastle, ${ }^{6,7}$ \\ Roger Hernández Diaz, ${ }^{8}$ María Luisa Avila-Aguero (10) , ${ }^{9,10}$ Kyaw Thu Ya, ${ }^{11,12}$ \\ David Williams, ${ }^{13}$ Jay Halbert (1) ${ }^{14}$
}

For numbered affiliations see end of article.

\section{Correspondence to}

Dr Jay Halbert, Department of Paediatrics, Royal London Hospital, London, UK; j.halbert@nhs.net

$J L G$ and SP are joint first authors.

Received 22 April 2020 Revised 27 August 2020 Accepted 27 August 2020 Published Online First 28 October 2020
Check for updates

(c) Author(s) (or their employer(s)) 2021. No commercial re-use. See rights and permissions. Published by BMJ.

To cite: Le Geyt J, Pach S, Gutiérrez JM, et al.

Arch Dis Child

2021;106:14-19.

\section{ABSTRACT}

Snakebite in children can often be severe or potentially fatal, owing to the lower volume of distribution relative to the amount of venom injected, and there is potential for long-term sequelae. In the second of a two paper series, we describe the pathophysiology of snakebite envenoming including the local and systemic effects. We also describe the diagnosis and management of snakebite envenoming including prehospital first aid and definitive medical and surgical care.

\section{INTRODUCTION}

The global burden of snakebite is large, disproportionately affecting children who live in low-income settings, and often leads to permanent physical and psychological sequelae. ${ }^{1-5}$ Due to their smaller size, children often present with more severe effects of snakebite, owing to their lower volume of distribution relative to the mass of injected venom. This higher ratio of venom to body mass can result in more rapid and severe neurotoxicity, coagulopathy and severe local tissue damage. ${ }^{6}$ This review describes the clinical presentation of snakebite envenoming in children, and its management, especially the challenges faced by clinicians in the lowincome settings where snakebite is most common.

\section{Snake venoms and antivenoms}

Venoms are injected by the snake either subcutaneously or intramuscularly, or rarely intravenously. Many venoms inflict local tissue damage at the anatomical site of injection. Rare cases result in areas of necrosis that occur away from the bite site, such as by some species of spitting cobras. Venom toxins are absorbed via lymphatic and blood vessels to reach the circulation, causing systemic effects. ${ }^{3}$

An estimated quarter of bites from venomous snakes are 'dry' bites (this proportion varies with snake species), meaning that venom is not injected and envenoming does not occur; ${ }^{7}$ it is important to differentiate the autonomic manifestations of fear from actual systemic envenoming.

Snake venoms are complex mixtures of proteins. Viperid snake venoms are particularly rich in metalloproteinases, serine proteinases and phospholipases A2. Elapid venoms contain high amounts of proteins of the three-finger toxin family and phospholipases A2. Many other protein families are also present in venoms and contribute to their toxicity,

\section{What is already known?}

- Snakebite in children disproportionately affects in low-income settings.

- Most healthcare settings manage cases of snakebite envenoming using a syndromic approach.

- Antivenom is the mainstay of effective treatment.

\section{What this study adds?}

- An updated review of the clinical presentation and management of snakebites in children.

- When and how to give antivenom in the paediatric population.

- An approach to management of snakebite in children, including what to do and what not to do.

such as C-type lectin-like proteins, disintegrins and dendrotoxins. ${ }^{3}$

Traditionally, antivenoms are preparations of immunoglobulins or immunoglobulin fragments prepared by immunising large animals, usually horses but sometimes sheep, with snake venom. After collection of blood and separation of plasma, antibodies are purified and preparations formulated to have a standard neutralising potency against the venoms used in the immunisation. ${ }^{8}$

\section{Local effects}

Local effects at the bite site occur in bites inflicted by the majority of species of the family Viperidae and by some species of the family Elapidae, such as the spitting cobras. These local effects are usually pain, swelling, ecchymosis and blisters, sometimes causing significant local tissue necrosis, including myonecrosis and cutaneous necrosis (see figure 1 ). ${ }^{9}$ Swelling is often more severe and widespread in children, although does tend to recover faster than in adults, with most completely recovered in 1 month. ${ }^{10}$ There is, therefore, a risk of developing compartment syndrome, depending on the site of the bite, the volume and type of venom injected, and the local reaction. ${ }^{11}$ 


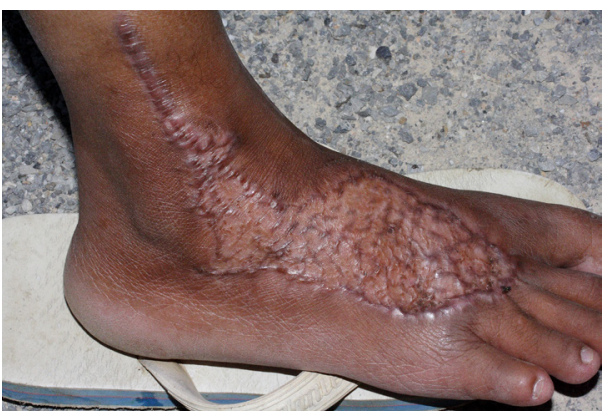

Figure 1 Scarring after cobra snakebite. Photograph by David J Williams.

\section{Systemic effects}

Envenoming can initially cause non-specific systemic symptoms of nausea, vomiting, back pain, headache, abdominal pain and dizziness. Unilateral focal tender lymphadenopathy is commonly reported as a non-specific sign of snake venom envenoming.

Systemic envenoming by species of the family Elapidae are mostly characterised by neurotoxic manifestations, that is, a descending neuromuscular paralysis which may end in bulbar paralysis and respiratory arrest. ${ }^{9}$ This is a consequence of neuromuscular blockade through the action of presynaptically or postsynaptically acting neurotoxins. ${ }^{12} 13$ Evidence of paralysis typically first appears as bilateral ptosis with or without ophthalmoplegia or diplopia. Some viperid species, such as the South American rattlesnake, also induce neuromuscular paralysis. ${ }^{14} \mathrm{~A}$ number of Australian elapid venoms also cause coagulopathy. ${ }^{15}$

Systemic manifestations of many viperid envenomings are typically associated with coagulopathy and bleeding, owing to the disruption of microvessel wall integrity by venom proteinases $^{16}$ and to a consumption coagulopathy. Some viper bites do not cause coagulopathy. In severe cases, hypovolaemia secondary to coagulopathy, capillary leakage and vasoactive and myocardial depressant toxins can precipitate cardiovascular shock. ${ }^{9}$ Some venoms, such as that of Russell's viper, cause a systemic capillary leakage syndrome, which contributes to hypovolaemia and shock. ${ }^{17} \mathrm{~A}$ number of elapid and viper species can cause acute kidney injury, owing to hypovolaemia, direct nephrotoxic effects, thrombotic microangiopathy or accumulation of myoglobin in renal tubules as a consequence of rhabdomyolysis. ${ }^{3}$ Recently, there have been increasing reports of sudden cardiorespiratory arrest associated with snakebite envenoming, due to cardiovascular toxicity of venoms. ${ }^{18}$

A number of 'colubrid' species can cause life-threatening envenomation characterised by haemorrhage and coagulopathy, and some species (notably African boomslang Dispholidus typus and Japanese yamakagashi Rhabdophis tigrinus) have caused fatalities.

In Africa and some parts of the Middle East burrowing asps in the genus Atractaspis are common causes of nocturnal snakebites. Clinical signs include local pain, moderate to severe local and regional swelling, oedema, lymphadenopathy, blister and bleb formation and subsequent necrosis. Some species can cause cardiovascular effects, including direct cardiotoxicity induced by endothelin-like toxins (sarafotoxins). ${ }^{19}$ Table 1 summarises the most important systemic effects of snakebite envenoming.

\section{Management of paediatric snake envenoming Community prehospital first aid}

The child should be kept calm and comfortable, as a hyperdynamic state can accelerate dissemination of venom. Immobilisation of the bitten part of the body, in a functional position below the level of the heart, reduces lymphatic absorption of the venom. ${ }^{20}$ The immobilised child should be transferred to a medical facility as quickly as possible, with the focus on airway and breathing support, prevention of aspiration (of vomitus or other fluids), oxygen administration and gaining intravenous access in an unaffected limb, ${ }^{20}$ if available.

Harmful practices such as incision, suction devices, snake stones, cryotherapy and tourniquets should not be used. ${ }^{21} 22$ Tourniquets, often still applied in rural settings, can increase local tissue destruction and cause gangrene and should be removed slowly. Pressure immobilisation bandages are useful in bites by elapids (neurotoxic snakes that do not cause local swelling) to reduce lymphatic flow. But they are not recommended in the case of viperid bites. If poorly applied, a pressure immobilisation bandage may cause increased local tissue damage. For these reasons, pressure immobilisation bandages are not recommended by the WHO in the majority of snake bites globally, although immobilisation of the affected limb is essential for all snakebites. $^{23}$

Remove objects such as rings, bangles or belts that can compress the bite site and increase oedema. Try to avoid the

Table 1 Mechanism, signs and symptoms of predominant snakebite envenoming systemic effects

\begin{tabular}{|c|c|c|}
\hline Mechanism & Typical symptoms and signs & Typical snakes associated \\
\hline \multicolumn{3}{|l|}{ Neurotoxic effects } \\
\hline $\begin{array}{l}\text { Blockade at presynaptic and/or postsynaptic sites of } \\
\text { neuromuscular junction }\end{array}$ & $\begin{array}{l}\text { Descending paralysis, ptosis, ophthalmoplegia, salivation, } \\
\text { dysphagia can progress to generalised flaccid paralysis } \\
\text { and respiratory arrest }\end{array}$ & Elapids (mambas, cobras, kraits, some rattlesnakes) \\
\hline \multicolumn{3}{|l|}{ Haemotoxic effects } \\
\hline Degradation of capillary basement membrane & Local and systemic bleeding & $\begin{array}{l}\text { Viperids (saw-scaled vipers, puff adders, Russell's viper, } \\
\text { rattlesnakes, lancehead vipers) }\end{array}$ \\
\hline Consumption of blood clotting factors, thrombocytopenia & $\begin{array}{l}\text { Venom-induced consumption coagulopathy Systemic } \\
\text { bleeding including epistaxis, gingival, gastrointestinal, } \\
\text { intracranial bleeding }{ }^{42}\end{array}$ & Viperids, some colubrids (eg, boomslangs and vine snakes) \\
\hline $\begin{array}{l}\text { Vasoactive substances in venoms or release of } \\
\text { endogenous vasoactive substances }\end{array}$ & Increased in vascular permeability & Viperids, atractaspids \\
\hline \multicolumn{3}{|l|}{ Renal effects } \\
\hline $\begin{array}{l}\text { Renal impairment from direct nephrotoxicity, } \\
\text { shock, thrombotic microangiopathy, hypovolaemia, } \\
\text { rhabdomyolysis }\end{array}$ & Electrolyte disturbances, acute kidney injury & $\begin{array}{l}\text { Viperids (Russell's viper, South American rattlesnake) } \\
\text { Elapids (New Guinea small-eyed snakes, Australian tigers } \\
\text { snakes, black snakes and taipans) }\end{array}$ \\
\hline
\end{tabular}




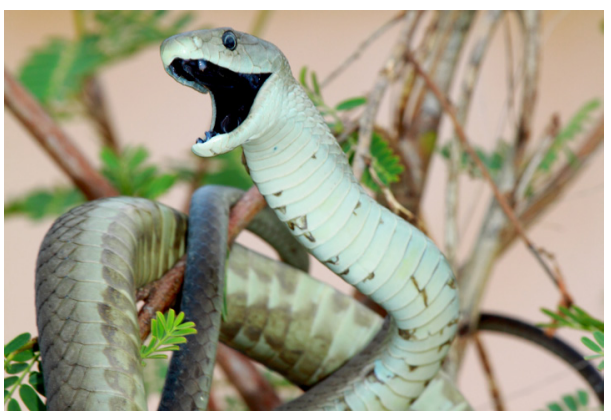

Figure 2 Black mamba (Dendroaspis polylepis). Photograph by David J Williams.

child eating or drinking. Administration of analgesia other than paracetamol is best avoided.

Photographs should be taken of the snake whenever possible to aid in identification, but snakes, including dead snakes, should never be handled (see figure 2 ). ${ }^{9}$

\section{Diagnosis}

The diagnosis of snakebite envenoming can be challenging in paediatric cases. In many countries, a syndromic approach is successfully used. ${ }^{22} 24$ This means the child's clinical and laboratory abnormalities suggest the type of snake responsible for the bite, which in turn helps to select the appropriate antivenom. Only a small number of high-income countries, such as Australia, have enzyme immunoassay tests to identify the presence of a specific snake venom. These tests are particularly useful when the local snake fauna is diverse, the clinical manifestations from various snake bites are similar, and specific antivenom is needed.

Envenomated children may not present with a clear history of snakebite, but present with paralysis, seizures or coagulopathy of unknown aetiology. A high index of suspicion should be maintained, especially in children with coagulopathies of unknown origin that persist despite treatment. Examining the entire body surface of the child thoroughly-including scalp-for the presence of fang marks is essential. However, fang marks or local pain may not be evident in some snake envenoming, such as krait (Bungarus). In rural South and Southeast Asia, children with krait envenoming often present with abdominal pain and early neurological signs.

\section{Management at a health facility}

When a child arrives in hospital, an ABCDE (airway, breathing, circulation, disability, exposure) approach ${ }^{25}$ should be followed initially. Key points from the history should include the time of the bite, a description or photograph of the snake (see figure 3),

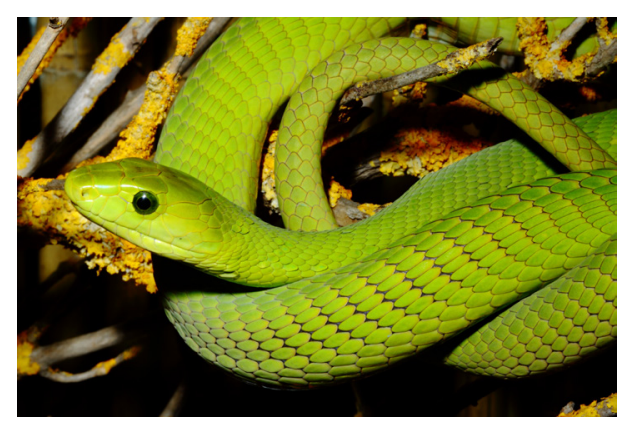

Figure 3 Eastern green mamba (Dendroaspis angusticeps). Photograph by David J Williams. first-aid measures that were used, other medical conditions and food or drug allergies. ${ }^{26}$

The provision of adequate analgesia is essential although some snakes cause almost no local pain or tissue necrosis during envenoming. Most opioids and benzodiazepines should be avoided in any neurotoxic envenomings and most haemotoxic bites (ie, those associated with bleeding and coagulopathies) due to reported venom potentiation but may have a role in cytotoxic bites. Ketamine is a safe analgesic commonly used in low and middle income country settings. ${ }^{27}$ A quick bedside test for suspected bites from haemotoxic snakes is the $20 \mathrm{~min}$ whole blood clotting test. If the blood clots, then the risk of haemotoxic envenoming is unlikely. ${ }^{28}$

The child should receive supportive care and be closely and frequently monitored (see table 2), particularly for evidence of airway or respiratory compromise, progressive paralysis, hypotension or cardiovascular collapse, bruising or bleeding and kidney impairment.

If significant neurotoxic envenoming has occurred, then early intubation and ventilation is advocated. Antivenom administration may reduce the time of ventilation from an average of 7 to 4 days. Early use of renal replacement therapy for oliguric or hyperkalemic acute kidney injury is advised where available.

The use of antibiotics continues to be controversial, but broad-spectrum antibiotics may be recommended, particularly in tropical countries, where the incidence of bacterial infections of snakebite wounds is higher. Their role can also be argued in cases of cytotoxic syndromes once the necrosis is established to prevent subsequent wound infection. ${ }^{29}$

Intramuscular injections should not be given when a coagulopathy is present. Tetanus toxoid and tetanus immunoglobulin should be given early if the child is not immunised.

Once antivenom therapy is administered, the response to the medication must be carefully assessed. If possible, consultation with a regional toxinologist or paediatrician with experience in dealing with snakebites is recommended.

\section{Antivenom}

Antivenom is the only specific treatment to reverse or prevent the dangerous effects of snakebite and is highly efficacious in most cases if administered in a timely fashion. ${ }^{3}$ This is highlighted by the inclusion of snake antivenom immunoglobulins in the WHO List of Essential Medicines, meaning it should be available in all settings where venomous snakes are present. ${ }^{30}$ Despite this, the availability and accessibility of antivenoms of many regions of sub-Saharan Africa and Asia is very limited. ${ }^{31}$

Identification of the snake species to choose the correct antivenom is difficult, as in most cases the snake is not brought to the health facility and in some cases a syndromic approach is used. The majority of antivenoms are, however, polyspecific, that is, able to neutralise venoms of several species from one or more groups of snakes. In Africa and (with few exceptions) most Asian countries, antivenoms are polyspecific for both viper and elapid venoms, whereas in North and Latin America polyspecific antivenoms tend to be for different genera of vipers, while coral snake antivenoms are separate products. In Australia and New Guinea, different species of elapid snakes can cause different envenoming syndromes but a polyspecific antivenom suitable for almost all these species is available, along with a range of monospecific products. Clinicians can often identify the genus of the snake that inflicted the bite based on the clinical and laboratory abnormalities, and the decision on whether or not to administer 
Table 2 Monitoring and supportive care considerations

\begin{tabular}{ll}
\hline Cardiovascular & Pulse, blood pressure, capillary refill time, urine output, ECG \\
Respiratory & $\begin{array}{l}\text { Airway patency and protection, oxygen saturation, ventilation adequacy, pulmonary function tests (peak flow and inspirometers), } \\
\text { blood gases, capnography if ventilated }\end{array}$ \\
\hline Neurological & Cranial nerves examination, peripheral neurological examination, pain (avoid opiates where possible) \\
\hline Laboratory investigations & $\begin{array}{l}\text { Blood (full blood count), prothrombin time/INR, APTT, fibrinogen, D-dimer, urea, creatinine, creatine kinase, electrolytes, calcium, } \\
\text { phosphate, uric acid, haemoglobinuria, myoglobinuria (in low-income settings, these may differ, with tests such as 20 min whole } \\
\text { blood clotting test (WBCT 20 min) and packed cell volume more readily available) }\end{array}$ \\
\hline Local site & $\begin{array}{l}\text { Assessment for infection, swelling, tissue necrosis, early surgical involvement if debridement necessary, compartment pressures if } \\
\text { clinical suspicion of compartment syndrome }\end{array}$ \\
\hline
\end{tabular}

antivenom and which antivenom should be used can be based on this clinical identification. ${ }^{2122}$

In general, antivenom should, if available, be administered to all patients who have evidence of:

1. Systemic manifestations of envenoming.

2. Severe local and regional effects of envenoming, particularly those with substantial swelling, oedema or skin lesions extending to two major joints from the bite site (eg, past the knee following a bite on the foot or to the pelvis after a bite above the ankle).

Health workers should be guided by available national or regional snakebite protocols, and if in doubt should seek expert advice.

Antivenom should ideally be administered intravenously by infusion; however where this is not possible, it can be delivered by slow intravenous push at a rate of no more than $2 \mathrm{~mL} /$ minute. For intravenous infusion, paediatric burettes or $100 \mathrm{~mL}$ normal saline infusion bags are useful for dose dilution and volumecontrolled administration in the absence of mechanical infusion pumps. Dosages and regimens of antivenom administration vary and there is a paucity of randomised controlled trials and evidence regarding best use, with none specifically focused on children. ${ }^{32}$ Antivenom has reportedly been used in children as young as a 27 -day-old neonate. ${ }^{33}$ The doses of antivenom used in children are the same as adult doses, as the volume of venom injected does not depend on the size of the victim. However, the volume of saline solution in which antivenom is diluted is generally lower than that used in adult patients to avoid fluid overload. When clinical manifestations of envenoming do not subside several hours after antivenom infusion, the administration of a second dose of antivenom must be considered.

\section{Reactions to antivenom}

Antivenom is associated with both early (type I IgE and non-IgE mediated) acute adverse reactions, and late 'serum sickness' reactions (type III hypersensitivity reactions). Acute allergic reactions after antivenom administration occur in $2 \%$ to $50 \%$ of treated snakebite victims, ${ }^{34}$ depending on the type of antivenom and the dose. There is no evidence to support giving antihistamines or hydrocortisone to prevent early adverse reactions to antivenom, ${ }^{35}$ although preadministration of epinephrine in high-risk cases may reduce such reactions. ${ }^{36}$ When reactions occur, epinephrine should be used, in addition to antihistamines and steroids, with care taken for the sedative effects of first-generation $\mathrm{H} 1$ antihistamines. However, none of the randomised controlled trials performed focused on children. ${ }^{33}$ Serum sickness typically occurs between 5 and 24 days postadministration of antivenom and involves fever, urticarial rash, arthralgia, malaise, lymphadenopathy and occasionally even renal failure. These reactions generally respond well to prednisolone. ${ }^{26}$

\section{Surgical care of snakebite management}

Once the patient has been assessed and initial supportive management underway as previously described, local wound assessment follows. Surgical wound management is particularly important in cytotoxic bites and with eye-sprays from some of the spitting cobras.

For eye-splashes, extensive eye irrigation with water or milk with the use of topical lignocaine is crucial. ${ }^{37}$

Wounds should be cleaned after any required swabs or specimens are taken, preferably with a chlorhexidine-based antiseptic. The wound should be inspected for bleeding, skin necrosis, blistering and firmness of surrounding compartments. All wounds will demonstrate some degree of inflammation, and very early infection is unlikely. Current surgical practice is to deroof blisters and wash wounds, covering them with a non-adherent silver-containing (or honey-based) dressing. The wounds should be inspected for progression in the first 24 hours, thereafter reviewing at least every 48 hours. ${ }^{37}$ Only once the wound edges demarcate (around day 5-7 postbite) should formal conservative debridement be performed. Various vacuum-assisted closure techniques allow granulation tissue to develop and reduce wound sepsis rates. Split skin grafting or tissue flaps may be required at a later date. ${ }^{37}$

Fasciotomy is often advocated for cytotoxic bites but is actually seldom required. Clinical assessment of peripheral perfusion includes capillary refill time and palpation for peripheral pulses and compartment tightness. However, the diagnosis of compartment syndrome in small children is particularly difficult. Fasciotomy should not be performed without first assessing the compartment pressures; this can be done using either a commercially purchased device or homemade versions, for example, a cannula introduced into the compartment and connected to a pressure transducer or manometer. ${ }^{38}$ If fasciotomy is indicated, it must be completed in each compartment in the relevant limb and should be performed in conditions where replacement of coagulation factors is available if indicated in a patient with coagulopathy.

\section{Traditional medicine}

Traditional methods to deal with snakebite envenoming include local incisions, herbal remedies, use of tourniquets (see figure 4), oral suction at the bite, recitation of mantras and electric shock. These are ineffective, but some of these can be harmful causing tissue necrosis, bleeding or infection. The use of traditional healers often leads to delays in accessing effective conventional medical treatment (including antivenom), commonly with delays of more than 1 day between snakebite and medical facility attendance in sub-Saharan Africa. ${ }^{39}$ Delayed presentation at health facilities due to diversion to traditional practitioners can lead to fatal outcomes. 


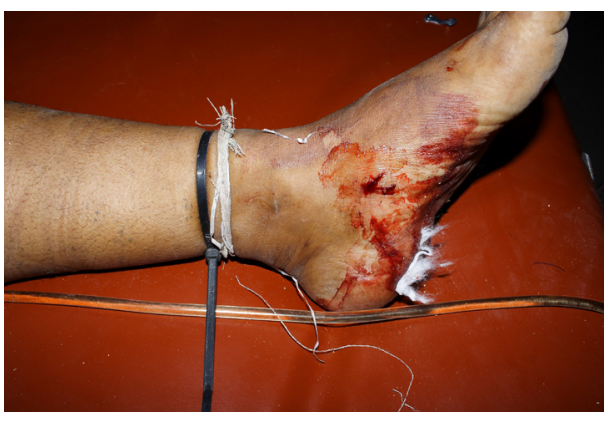

Figure 4 Dangerous traditional first-aid techniques such as tourniquets are not recommended. Photograph by David J Williams.

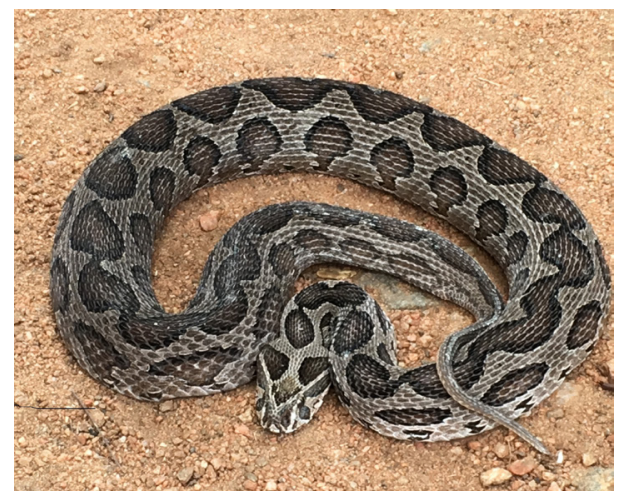

Figure 5 Russell's viper. Photograph by Kalana Prasad Maduwage.

There is significant geographical variation in the use of traditional medicine as first-line treatment. Overall, in sub-Saharan Africa over $75 \%$ of people use traditional healing methods first, although in Zimbabwe this figure is only 16\%. ${ }^{39}$ A large rural survey in Bangladesh found that only 3\% of victims go directly to a medical doctor or hospital. ${ }^{40}$ Community engagement should focus on education promoting the rapid transport of snakebite victims to the nearest health facility, as has been done in Nepal with the use of motorcycles. ${ }^{41}$

\section{CONCLUSION}

Most deaths and serious sequelae related to snakebites are preventable if there is treatment (safe and effective antivenom and supportive care) available locally, and if there are health staff trained in the management of snakebite envenoming.

The management of snakebite envenoming faces significant challenges as it disproportionately affects those in rural communities in low-income countries. Community education of prehospital first aid and the potential negative impact of traditional medicine are crucial. Globally most healthcare settings manage cases of snakebite envenoming using a syndromic approach. Paediatric cases are particularly challenging to manage clinically due to the lower volume of distribution of venom and the potential for lifelong permanent sequelae from tissue damage. Much work needs to be done to look specifically at antivenom dosing and regimens, as well as at ancillary therapies, in children.

\section{Author affiliations}

'Paediatric Emergency Medicine, Chelsea and Westminster Healthcare NHS Trust, London, UK

${ }^{2}$ General Medicine, Royal Free London NHS Foundation Trust, London, UK

${ }^{3}$ Instituto Clodomiro Picado, Facultad de Microbiología, Universidad de Costa Rica, San José, Costa Rica

${ }^{4}$ African Center of Excellence on Population Health and Policy, Bayero University, Kano, Nigeria

\section{Case vignette}

A boy aged 5 years, Aung, was walking in sandals playing in the long grass on the way to school in rural Myanmar, when he was bitten by a snake on his lower leg. His teenage brother, Kyaw, saw the snake retreating, and took a photograph (see figure 5) on his mobile phone.

\section{What first aid could the brother attempt?}

Kyaw carried Aung back to their local village over the following half hour, where a traditional healer was summoned, who performed several local incisions. However, Aung's leg pain continued to get worse over the next few hours, and he became drowsy. His vomiting began to contain blood, his eyes became bloodshot, and he began bleeding from his gums.

\section{What type of signs was Aung beginning to show? What other signs might you expect?}

The decision was made to travel to the nearest medical facility, which was 2 hours away, in the village shop's pick-up truck. He continued to vomit throughout the journey, with increasing amounts of blood. By the time Aung arrived at the medical facility, he had bilateral ptosis, and generalised muscle pain and tenderness.

\section{As the receiving clinician at this small health facility, how} would you assess and treat this child?

Aung received a careful assessment and regular monitoring of his airway, respiratory effort, pulse, blood pressure, capillary refill time, urine output, and central and peripheral neurological examinations. He was given oxygen but did not require any additional ventilatory support. Intravenous fluids were required for the first 24 hours to treat hypovolaemia. Basic blood tests for FBC, renal function, and coagulation were able to be performed every 48 hours.

Despite the facility having been out of stock of antivenom for months, luckily a delivery had been made that week. Aung received antivenom, bought with donations made by relatives and neighbours. He was successfully discharged from hospital a week later.

${ }^{5}$ Department of Biochemistry, University of Peradeniya, Peradeniya, Kandy, Sri Lanka ${ }^{6}$ Trauma Service, Inkosi Albert Luthuli Central Hospital, Durban, South Africa ${ }^{7}$ Department of Surgery, University of KwaZulu-Natal, Durban, South Africa ${ }^{8}$ Pediatrics, Hospital Nacional Cayetano Heredia, Lima, Peru

${ }^{9}$ Pediatric Infectious Diseases, Hospital Nacional de Niños, San Jose, Costa Rica ${ }^{10}$ Center for Infectious Disease Modeling and Analysis, Yale University School of Public Health, New Haven, Connecticut, USA

${ }^{11}$ Department of Paediatric Nephrology, University of Medicine, Mandalay, Myanmar ${ }^{2}$ Department of Paediatrics, University of Medicine, Mandalay, Myanmar

${ }^{13}$ No affiliation, West Wallsend, New South Wales, Australia

${ }^{14}$ Department of Paediatrics, Royal London Hospital, London, UK

Twitter Timothy Craig Hardcastle @vemadoc, María Luisa Avila-Aguero @maluavi and KyawThu Ya @k.thura.ped@gmail.com

Contributors The idea for this paper was formulated by the lead author JH. All coauthors were involved in the design of the paper. An initial literature review was performed by $\mathrm{JH}$ and then further updated by all coauthors. The first draft of the paper was written by SP, JLG and JH. This was then reviewed and revised by all coauthors.

Funding The authors have not declared a specific grant for this research from any funding agency in the public, commercial or not-for-profit sectors.

Competing interests None declared.

Patient consent for publication Obtained.

Provenance and peer review Not commissioned; externally peer reviewed. 
Data availability statement No data are available. Review article.

\section{ORCID iDs}

Jacqueline Le Geyt http://orcid.org/0000-0001-9540-9463

María Luisa Avila-Aguero http://orcid.org/0000-0002-1979-0431

Jay Halbert http://orcid.org/0000-0003-1048-5876

\section{REFERENCES}

1 Chippaux J-P. Snakebite envenomation turns again into a neglected tropical disease! J Venom Anim Toxins Ind Trop Dis 2017;23:38.

2 WHO. Snakebite Envenoming- a strategy for prevention and control, 2019. Available: https://www.who.int/snakebites/resources/9789241515641/en/ [Accessed 22 Oct 2019].

3 Gutiérrez JM, Calvete JJ, Habib AG, et al. Snakebite envenoming. Nat Rev Dis Primers 2017;3:17079.

4 Kasturiratne A, Wickremasinghe AR, de Silva N, et al. The global burden of snakebite: a literature analysis and modelling based on regional estimates of envenoming and deaths. PLoS Med 2008:5:e218.

5 Harrison RA, Hargreaves A, Wagstaff SC, et al. Snake envenoming: a disease of poverty. PLoS Negl Trop Dis 2009;3:e569.

6 Kshirsagar VY, Ahmed M, Colaco SM. Clinical profile of snake bite in children in rural India. Iran J Pediatr 2013:23:632-6.

7 Juckett G, Hancox JG. Venomous snakebites in the United States: management review and update. Am Fam Physician 2002:65:1367-74.

8 León G, Vargas M, Segura Álvaro, et al. Current technology for the industrial manufacture of snake antivenoms. Toxicon 2018;151:63-73.

9 Warrell DA. Snake bite. Lancet 2010;375:77-88.

10 Warrell DA. Treatment of bites by adders and exotic venomous snakes. BMJ 2005:331:1244-7

11 Brenes-Chacón H, Gutiérrez JM, Camacho-Badilla K, et al. Snakebite envenoming in children: a neglected tropical disease in a Costa Rican pediatric tertiary care center. Acta Trop 2019;200:105176.

12 Barber CM, Isbister GK, Hodgson WC. Alpha neurotoxins. Toxicon 2013:66:47-58.

13 Dixon RW, Harris JB. Nerve terminal damage by beta-bungarotoxin: its clinical significance. Am J Pathol 1999:154:447-55.

14 Frare BT, Silva Resende YK, Dornelas BdeC, et al. Clinical, Laboratory, and Therapeutic Aspects of Crotalus durissus (South American Rattlesnake) Victims: A Literature Review. Biomed Res Int 2019:2019:1-7.

15 White J. Snake venoms and coagulopathy. Toxicon 2005;45:951-67.

16 Gutiérrez JM, Escalante T, Rucavado A, et al. Hemorrhage caused by snake venom metalloproteinases: a journey of discovery and understanding. Toxins 2016;8:93.

17 WHO. Guidelines for the management of snakebites, 2006. Available: https://www. who.int/snakebites/resources/9789290225300/en/ [Accessed 23 Oct 2019].

18 Maduwage K. Sudden cardiorespiratory arrest following Sri Lankan snake envenoming. Sri Lanka Medical Association Newsletter 2019;16.

19 Mahjoub Y, Malaquin S, Abou Arab O, et al. Echocardiographic evaluation of the acute cardiovascular effects of an endothelin-like peptide extracted from the venom of Atractaspis irregularis. Cardiovasc Toxicol 2017;17:208-14.

20 Parker-Cote J, Meggs WJ, Aid F. First aid and pre-hospital management of venomous snakebites. Trop Med Infect Dis 2018;3:45.
21 WHO Regional Office for Africa. World Health organization guidelines for the prevention and clinical management of snakebites in Africa, 2010. Available: https:// www.who.int/snakebites/resources/9789290225300/en/ [Accessed 23 Oct 2019].

22 Blaylock RS. The identification and syndromic management of snakebite in South Africa. SA Fam Pract 2005;47:48-53.

23 WHO. Snakebite envenoming. Available: https://www.who.int/snakebites/treatment/ en/ [Accessed 28 Jun 2020].

24 Muller GJ, Modler H, Wuim CA. Snake bite in southern Africa: diagnosis and management. CME 2012;30:362-82.

25 The ABCDE Approach. Resuscitation Council guidelines 2014-2018. Available: https:// www.resus.org.uk/resuscitation-guidelines/abcde-approach/ [Accessed 7 Jan 2020].

26 Gold BS, Dart RC, Barish RA. Bites of venomous snakes. N Engl J Med 2002;347:347-56.

27 Pillay L, Hardcastle T. Collective review of the status of rapid sequence intubation drugs of choice in trauma in low- and middle-income settings (prehospital, emergency department and operating room setting). World J Surg 2017;41:1184-92.

$28 \mathrm{WHO} /$ Regional Office for South-East Asia. Guidelines for the management of snakebites. $2^{\text {nd }}$ edition, 2016. https://www.who.int/snakebites/resources/ 9789290225300/en/. (Accessed 19 March 2020).

29 Avau B, Borra V, Vandekerckhove P, et al. The treatment of snake bites in a first aid setting: a systematic review. PLoS Negl Trop Dis 2016;10:e0005079.

30 Snake-Bite envenoming: a priority neglected tropical disease. Lancet 2017;390:2.

31 Williams D, Gutiérrez JM, Harrison R, et al. The global snake bite initiative: an antidote for snake bite. Lancet 2010;375:89-91.

32 Sankar J, Nabeel R, Sankar MJ, et al. Factors affecting outcome in children with snake envenomation: a prospective observational study. Arch Dis Child 2013;98:596-601.

33 Jindal G, Mahajan V, Parmar VR. Antisnake venom in a neonate with snake bite. Indian Pediatr 2010;47:349-50.

34 Nuchpraryoon I, Garner P. Interventions for preventing reactions to snake antivenom. Cochrane Database Syst Rev 2000:CD002153.

35 Morais V. Antivenom therapy: efficacy of premedication for the prevention of adverse reactions. J Venom Anim Toxins Incl Trop Dis 2018:24:7.

36 de Silva HA, Pathmeswaran A, Ranasinha CD, et al. Low-Dose adrenaline, promethazine, and hydrocortisone in the prevention of acute adverse reactions to antivenom following snakebite: a randomised, double-blind, placebo-controlled trial. PLoS Med 2011;8:e1000435.

37 Hardcastle TC. Surgical aspects of snakebite. eSwatini Snakebite Symposium; 2-3 November, 2018.

38 WHO guidelines for the management of snakebites 2nd ED 2016 Annex 6. New Delhi South East Asia Regional Office; 2016

39 Chippaux J-P. Estimate of the burden of snakebites in sub-Saharan Africa: a metaanalytic approach. Toxicon 2011;57:586-99.

40 Rahman R, Faiz MA, Selim S, et al. Annual incidence of snake bite in rural Bangladesh. PLoS Negl Trop Dis 2010;4:e860.

41 Sharma SK, Bovier $\mathrm{P}$, Jha $\mathrm{N}$, et al. Effectiveness of rapid transport of victims and community health education on snake bite fatalities in rural Nepal. Am J Trop Med Hyg 2013:89:145-50

42 Ariaratnam CA, Thuraisingam V, Kularatne SAM, et al. Frequent and potentially fatal envenoming by hump-nosed pit vipers (Hypnale hypnale and $H$. nepa) in Sri Lanka: lack of effective antivenom. Trans R Soc Trop Med Hyg 2008;102:1120-6. 